\title{
Fotografia e alistamentos científicos: em torno de uma controvérsia sobre autenticidade
}

\author{
JORGE VENTURA DE MORAIS \\ Doutor em Sociologia (London School of Economics) \\ Professor da Universidade Federal de Pernambuco. \\ Recife, Brasil \\ venturademorais@gmail.com
}

Rosane ALENCAR

Doutora em Sociologia (Universidade Federal de Pernambuco) Professora da Universidade Federal de Pernambuco.

Recife, Brasil.

rosanealencar@gmail.com

Paulo Marcondes SoARES

Doutor em Sociologia (Universidade Federal de Pernambuco)

Professor da Universidade Federal de Pernambuco

Recife, Brasil.

paulomfsoares@gmail.com

\begin{abstract}
Resumo Analisamos as controvérsias em torno da fotografia intitulada "Morte do Miliciano", de Robert Capa, à luz da sociologia das associações de Bruno Latour. Acompanhamos o desenrolar dos debates entre duas posições antagônicas (a que diz que a foto teria sido posada e a outra, que Capa teria realmente fotografado alguém no momento mesmo da sua morte) através da utilização de um documentário em que a ciência e seus artefatos são alistados para defender uma determinada posição. Concluímos mostrando que, longe de tentar resolver sociologicamente a controvérsia, a sociologia das associações nos permite ter um entendimento dos diversos argumentos postos à prova pelas partes em disputa.
\end{abstract}

Palavras-chave: Fotografia; Robert Capa; Ciência; Instrumentos Científicos; Sociologia das Associações.

\section{Introdução}

C HEIO DE SIMPATIAS pelas forças republicanas da Espanha em 1936 - assim como diversos intelectuais e artistas daquela época -, Capa (2010) começou a fotografar a Guerra Civil na frente de batalha registrando-a de dentro de túneis, trincheiras, cidades etc.

Foi dessa forma - ou, pelo menos, assim se acreditou durante certo tempo - que ele tirou a foto (Figura 1) que o imortalizou para sempre entre os maiores fotógrafos do século XX e como "criador" do fotojornalismo de guerra. A controvérsia acerca da fotografia de Capa pode ser resumida através da pergunta a ela adicionada, como se vê na versão abaixo: real ou encenada? 


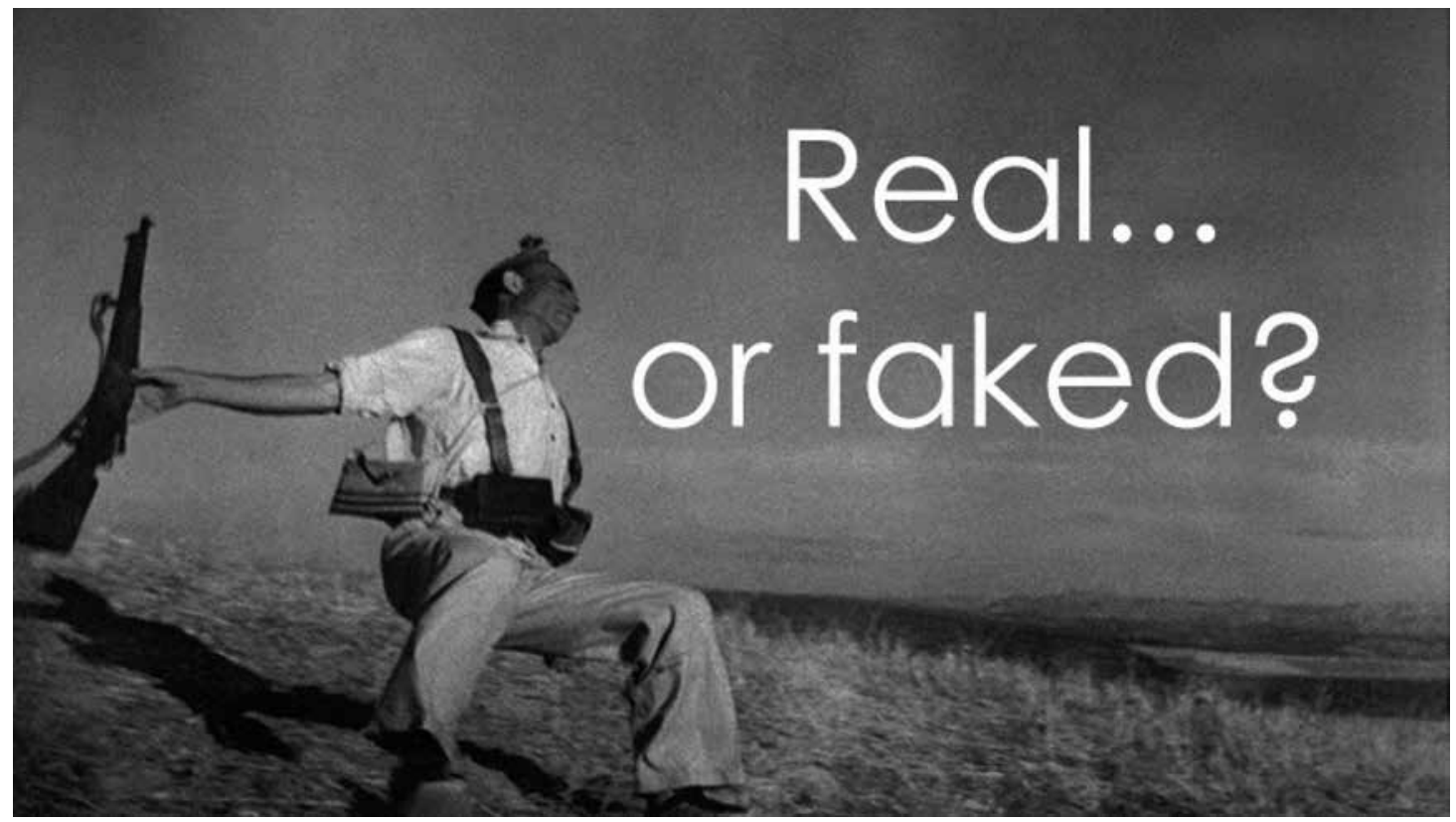

Figura $1^{1}$

Dúvidas sobre a foto sempre existiram, mas corriam através de cochichos. No entanto, de tempos para cá, tem havido várias vozes que contestam que ela tenha sido tirada no calor da batalha e que seja um retrato real da guerra. Em vez disso, apostam que ela foi encenada.

Para isto, vários meios têm sido utilizados. Houve atenção para o fato de que não teria havido batalha no dia e local relatados. Chamou-se atenção também para a posição do rifle e do corpo, inclusive com a utilização da foto seguinte, na sequência, cuja posição do corpo caído não seria condizente com a posição em que o miliciano teria sido atingido pelo tiro. Argumentou-se também acerca do fato de que não há sangue na camisa do morto, investigou-se qual teria sido a arma usada, a câmera utilizada por Robert Capa etc.

Já entre aqueles que defendiam e defendem a foto como tendo sido capturada por Capa em um momento supremo da brutalidade da guerra, procurou-se, primeiro, descobrir a identidade do miliciano - identificado inicialmente como Federico Borrell García -, o que foi confirmado por familiares como tendo sido morto no dia em que a foto fora tirada. Foi também argumentado que não tinha havido realmente uma batalha, mas tiroteios espaçados e que em uma destas ocasiões ocorreu a fatalidade com Borrell García (Cf. Martins, 2008, p.22 (nota 27)).

Com relação à sequência de fotos, procurou-se mostrar fotos anteriores - não posteriores - em que Capa fotografou, de dentro da trincheira, os republicanos em posição de combate, pelas costas. Isto mostraria porque Borrell García, na hora da morte, teria sido fotografado de frente - ele estaria correndo para dentro da trincheira - e não pelas costas.
E a ausência de sangue na camisa branca do miliciano? Bom, responderam os defensores de Capa: Borrell García foi atingido por um tiro de fuzil Magnum - descobriram a arma utilizada pelos franquistas - e, portanto, não teria tido tempo de sangrar no momento da foto.

Assim, vale registrar o problema sociológico de que nos ocupamos neste artigo: que argumentos e que alistamentos têm sido apresentados por estes dois 'partidos' na tentativa de tornar suas versões do fato histórico uma caixa preta (Cf. Latour, 2000)? Ou, parafraseando Chateauraynaud (2004; 2007, 2009a e 2009b), em consonância com uma sociologia da crítica, que provas cada uma das partes apresenta para estabelecer sua posição como a verdade?

Dado que uma sociologia da crítica não pretende ser uma sociologia crítica, desde logo afastamos um problema sociológico menor: não nos cabe dizer quem está certo ou errado neste debate. Assim, nosso foco se coloca na análise dos argumentos e práticas envolvidos no debate para tornar suas teses em caixas-pretas (Latour, 2000), isto é, como versões definitivas a partir do alistamento da ciência e de seus artefatos. Para isto, iremos seguir os atores humanos (experts, cientistas, fotógrafos, historiadores etc) e não humanos (máquinas fotográficas, instrumentos topográficos, satélites etc) e a própria ciência (topografia, cartografia, geografia, história, medicina forense etc) com o objetivo de acompanhar a abertura e tentativas de encerramento da controvérsia. Na perspectiva sociológica proposta aqui, argumentos são tratados como unidades elementares de significação que permitem análises comparativas de 
material complexo e heterogêneo (Chateauraynaud, 2007, p.3).

Dentre as diversas obras dedicadas a discutir a famosa foto de Capa, selecionamos para análise o documentário La Sombra del Iceberg, de Hugo Doménech (professor da Faculdade de Comunicação da Universidade Jaume I e de Castellón) e Raúl M. Riebenbauer (jornalista e cineasta), realizado no ano de 2007. Esta obra é importante porque parte de um foco analítico pouco explorado em obras anteriores: a dissecção da famosa fotografia é feita a partir não somente de depoimentos opinativos que possam revelar a "verdade", mas também - e o mais importante para os objetivos deste artigo - dos alistamentos da ciência e seus artefatos.

Em um processo bem lembrado por Bruno Latour em Ciência em Ação, os saberes científicos e tecnológicos pulam os muros da academia para as telas do cinema e da TV e para as mesas dos debates públicos, revelando assim o fato de que não há divisão entre sociedade e ciência; a sociedade, nos parece, seguindo Latour, é ciência e a ciência é sociedade.

\section{Arregimentação Teórica}

A concepção latouriana de prática científica pode ser compreendida a partir de uma série de conceitos elaborados que dão armadura a uma proposta teórico-metodológica de estudo da construção e constituição do conhecimento científico. O conceito de construção se refere ao processo material, lento e prático pelos quais as inscrições são feitas e as descrições são mantidas ou refutadas.

Para dar conta das controvérsias, Latour traz o conceito de campo agonístico (Cf. Latour, 1997, p.267268). Tal conceito refere-se à forma como fatos e artefatos são definidos em função de conexões entre vários enunciados que constituem os argumentos de força maior na controvérsia instalada. Já com o conceito de materialização, a importância é dada aos elementos materiais do laboratório na produção dos fatos. Tanto os equipamentos materiais como os componentes intelectuais fazem parte desse conceito. Um enunciado é estabilizado dentro do campo agonístico - reificado e integrado ao "saber-fazer" tácito ou ao equipamento material (Alencar, 2004).

Para designar os diferentes investimentos realizados pelos pesquisadores e as conversões entre diferentes aspectos do laboratório, Latour usa o conceito de credibilidade (Latour, 1997). Tal noção permite relacionar conceitos como credenciais, referências profissionais e o crédito acordado às crenças e resultados. Ou seja, a fusão dos elementos epistemológicos, econômicos e sociológicos.

Porém, interessante para o autor é considerar as circunstâncias. Tudo que se encontra no entorno da prática científica, seja a existência de um objeto do saber estável, seja a circulação desse mesmo objeto fora do laboratório de origem ou nas conversações diárias, acontece a partir de circunstâncias locais e idiossincráticas.

Por fim, todos esses conceitos podem ser sintetizados pela noção de móbiles immuables: síntese do processo de construção contingente e coletiva dos fatos científicos. A consideração da contingência nesse processo de construção da ciência é o que permite considerar que os fatos científicos, mesmo tendo sido reconhecidos como tal e apresentarem-se estáveis, estarão sujeitos a transformações desde que colocados novamente em discussão. Porém, apesar dessa instabilidade constitutiva, esses mesmos fatos podem transitar de um laboratório a outro, sem distorção ou perda de algum dos seus elementos constitutivos.

Em Pasteur: guerre et paix, suivi de Irréductions, Latour (1984), ao argumentar sobre a contingência da produção científica, considera que há uma conexão dos fatos internos com os externos dentro do laboratório e nas práticas científicas. Ao estudar o trabalho de Pasteur, o autor afirma que este cientista realizou uma revolução tanto no laboratório quanto a partir deste, na sociedade francesa. Dessa forma, não basta reconstruir o contexto social no qual a ciência se insere, mas mostrar como a ciência e seus conteúdos influenciam a sociedade, ordenando-a ou desordenando-a, reformando-a ou mantendo-a.

Tais conceitos possibilitarão, na nossa análise, a dissecação dos argumentos apresentados no documentário. Ao longo das sete partes, acompanharemos a "montagem" do campo agonístico que envolve a controvérsia sobre as circunstâncias práticas da fabricação da fotografia de Robert Capa. A partir das modalizações - positivas ou negativas (Latour, 2000, p.42-47) - poderemos acompanhar a controvérsia estabelecida no documentário. No nosso entender, três assertivas são apresentadas no documentário: (a) a foto foi tirada no dia 5 de setembro de 1936, às 17h, em Cerro Muriano, Córdoba, e mostra o momento exato da morte de $\mathrm{Fe}-$ derico Borrell García; (b) a foto NÃO foi tirada às $17 \mathrm{~h}$, nem foi em Cerro Muriano e não mostra o momento exato da morte de Federico Borrell García, nem a pessoa é Federico Borrell García; (c) a foto foi tirada às $8 \mathrm{~h}$, em Cerro de la Coja e é uma encenação da morte de uma pessoa da qual não se sabe o nome. Tais assertivas representam, nesse contexto, uma gradação que vai de uma modalidade positiva a uma negativa.

Assim, observaremos na análise o aspecto coletivo da construção dos fatos a partir dos contra-argumentos apresentados. Ou seja, estaremos diante do aspecto prospectivo do que é dito e a forma como será reelaborada por outros. Perceberemos que, quanto mais se avança nas controvérsias, mais seremos levados pelas tecnicalidades. Serão arregimentados amigos de Robert Capa, argumentos anteriores serão empilhados, encenados e enquadrados nos diferentes contextos e conteúdos selecionados pelos cineastas para tornar a tese defendida numa caixa preta. 


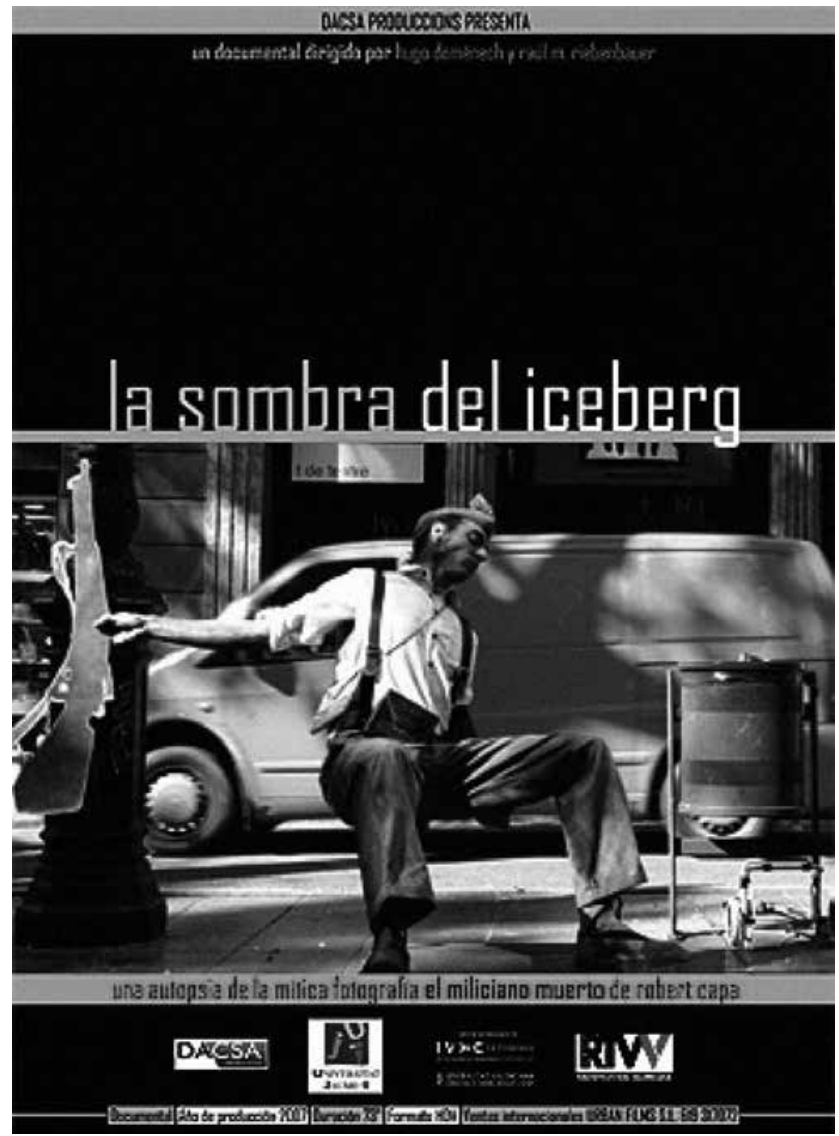

Figura 2 - Cartaz do documentário 'La sombra del iceberg', de Raúl M. Riebenbauer y Hugo Doménech / Fonte: Foto Dacsa

\section{O Campo Agonístico Analisado: - Documentário La Sombra del Iceberg}

Em um 'passeio' que vai desde as humanidades (História), passando pela Ciência Forense, chega-se à utilização da Astrofisica. Todos estes saberes acadêmicos - mais seus artefatos e suas lógicas próprias de argumentação - são trazidos a público na tentativa de elucidar a foto de Robert Capa.

Pretendemos apresentar neste artigo a própria divisão "nativa" da controvérsia para revelar os usos da ciência e da tecnologia e dos seus artefatos. Nesse sentido, acompanharemos a trilha das associações que compõem o documentário seguindo os traços deixados pelos documentaristas nos alistamentos apresentados desde a abertura ao encerramento do documentário. Ao rastrearmos as conexões entre os diferentes argumentos estaremos interessados tão somente, como diria Latour (2012), em seguir os atores e não em resolver as controvérsias.

"A diferença entre um texto comum em prosa e um documento técnico é a estratificação deste último. O texto é organizado em camadas" (Latour, 2000, p. 81). E assim o é este documentário. Os documentaristas dividem o filme em seis partes (o quê?; quem?; onde?; quando?; como?; por quê?), que constituem cada uma delas uma camada superposta sobre as outras de forma a ir aos poucos revelando os pontos fracos da versão oficial acerca da fotografia de Robert Capa.

O documentário, nomeado pela imprensa espanhola como "autopsia al miliciano de Robert Capa"2, defende que a imagem foi uma genial encenação. Para tanto, realiza uma autópsia sobre o miliciano e apresenta um exame profundo de sua identidade - a partir de detalhes da fotografia - para comprovar a tese da encenação, foco do documentário.

A autópsia inicia-se pelo questionamento da hora em que o miliciano morreu. Recorre-se à astrofisica: os realizadores acreditam demonstrar que a foto não foi realizada às cinco horas da tarde, mas sim às nove horas da manhã quando não havia nenhuma batalha na região. Em seguida, a partir de um estudo anatômico forense e da medicina legal, conclui-se que Frederico Borrell Garcia não é o miliciano morto da fotografia. Também se questiona a autoria da foto estabelecendo a dúvida pelo fato de Gerda Taro (companheira de Robert Capa) trocar de câmera com ele, assim como enviar suas próprias fotos como o nome de Robert Capa. Por fim, o documentário sustenta sua argumentação com o reconhecimento de Richard Whelan (biógrafo oficial de Capa) de que Cornell Capa, irmão de Robert, teria alguns negativos da série original.

Interessante observar que a argumentação apresentada no documentário apoia-se fortemente nas ciências já citadas, assim como em personagens centrais da história oficial desta fotografia. Assim, faz-se necessário a descrição e identificação dos vários personagens que são alistados no documentário, como aliados ou não, em relação à tese defendida pelos documentaristas.

Os enunciados em defesa da tese de que a foto foi encenada serão arregimentados pelos seguintes personagens alistados no documentário: a) Patrick Jeudy, cineasta, autor, do documentário "Robert Capa, l'homme qui voulait croire a sa legende"; b) Orestes Brotons, filho de Mario Brotons, historiador que em 1995 afirmou que o miliciano da fotografia era Federico Borrell ‘Taino'; c) Fernando Verdú, médico forense do Departamento de Medicina Legal y Forense da Universidade deValencia; d) Enric Marco, astrofísico da Universidade deValencia; e e) Josep V. Monzó, chefe de Fotografía do Instituto Valenciano de Arte Moderno (IVAM).

Do outro lado, na defesa de que a foto não é uma encenação, os personagens alistados são: a) John G. Morris, amigo pessoal de Robert Capa, uma das cinco pessoas vivas que conheceram Robert Capa; b) Richard Whelan, biógrafo oficial e executor da obra de Robert Capa, um dos grandes defensores da veracidade da fotografia; e c) Michel Lefebvre, jornalista do Le Monde, 

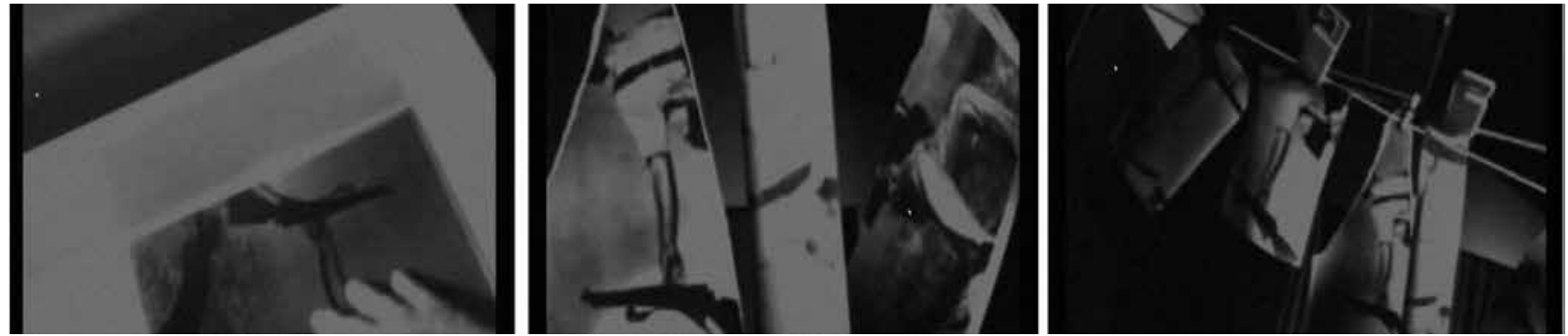

Figura 3 - Sequência da Revelação Contemporânea da Foto de Capa / Fonte: Fotograma do Documentário

colecionador e especialista na Guerra Civil Espanhola e na obra de Capa.

Assim, na sequência dos argumentos destes personagens e dos alistamentos realizados pelos documentaristas, vamos observar, a partir do aparato conceitual de Latour, os diversos empilhamentos de fatos e artefatos, assim como de personagens em que modalizações de natureza positiva e negativa se intercambiam na "autópsia" realizada pelos documentaristas da foto de Robert Capa.

\section{Seguindo os Alistamentos da Ciência: a Fabricação da Tese da Encenação}

O documentário introduz a controvérsia a partir da ciência, da narração jornalística e histórica. A abertura do documentário traz imagens que evocam o contexto de produção de conhecimento científico - um laboratório e instrumentos utilizados no processo de revelação fotográfica, assim como duas narrativas jornalísticas que descrevem o contexto histórico de produção da fotografia. Nessas duas narrativas, encontramos modalizadores que introduzem a dúvida em relação à produção da fotografia: "uma enorme fotografia.A primeira que capturou o instante da morte. Isso é o que conta a história" (Tempo: 2:20-2:30/74:14min) e "uma importante fotografia da suposta morte do miliciano
Frederico Borrel" (Tempo: 2:44/74:14min. Ênfase nossa). Assim, a controvérsia é introduzida a partir da dúvida em relação à identidade do miliciano.

Para trazer mais força na direção da dúvida colocada, a narração afirma que a criação dos personagens Robert Capa e de sua amante Gerda Taro (Figura 4) teve por motivação "triplicar a venda de suas fotografias" (Tempo: 3:24-3:26/74:14min) e que os dois fotógrafos eram comprometidos com a causa republicana espanhola. Nessa mesma direção, o documentário segue apresentando um processo de alistamento de argumentos a partir de diversos atores que constituem a controvérsia e, ao mesmo tempo, explicita o confronto com os que defendem que a fotografia é o registro do momento da morte de um miliciano para, em seguida fortalecer a tese de que o miliciano morto não é Federico Borrel, por meio de múltiplas narrativas e objetos da ciência.

Como aqui se estabelece com quem as alianças serão firmadas e contra quem se vai "lutar", é importante descrever com detalhes as pessoas e suas posições vis-à-vis a foto.

\section{O Quê?}

A primeira parte tem um tempo maior dedicado ao estabelecimento de alguns personagens importantes no campo dos defensores e não defensores da versão de Robert Capa.
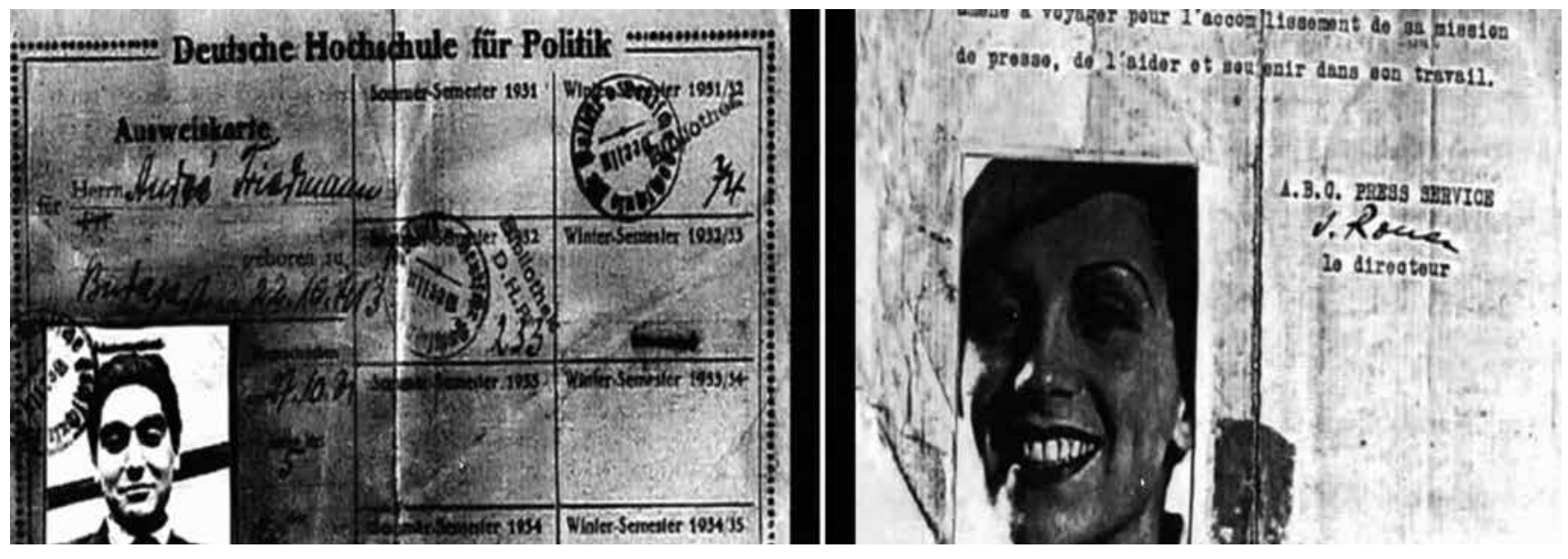

Figura 4 - Registros de Identidade de Robert Capa e Gerda Taro / Fonte: Fotograma do Documentário 


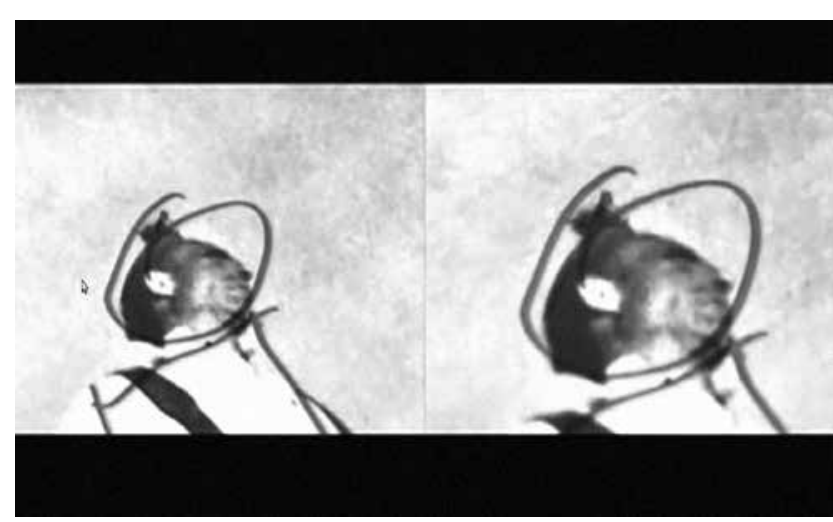

Figura 5 - Detalhe do Trabalho em Laboratório Para Identificação do Miliciano Morto / Fonte: Fotograma do Documentário

O trecho em que a ciência é alistada é relativamente curto, mas rico em implicações. Os cineastas alistam Fernando Verdú, especialista forense da Universidade de Valência. O primeiro ponto abordado é: em que parte do corpo se deu o impacto da bala? Se tivesse sido na cabeça, ela teria sido destroçada. Como prova, se mostra uma foto da cabeça de J.F. Kennedy quando assassinado. Mas nada disso é visto na foto do miliciano. O que, por muito tempo, se pensou que fosse uma marca do tiro é, na verdade, uma parte do gorro do miliciano. Por outro lado, para se matar uma pessoa desta maneira, argumenta Verdú, ela teria de ser atingida em um centro vital, como o coração, mas não há mancha de sangue na camisa.

O segundo ponto é a posição do corpo. O que lhe parece é que se o miliciano viesse correndo - como sustenta a versão oficial - e tivesse sido atingido por uma bala, teria de ter sido um projétil de grande potência disparado de uma distância muito próxima - e não a $100 \mathrm{~m}$ ou $150 \mathrm{~m}$, ou mais, acrescentamos, como numa batalha real - para frear a corrida e ainda jogar o corpo para trás.

Como desdobramento deste ponto, Verdú analisa ainda a relação entre a mão direita do miliciano e sua arma, um fuzil Mauser, calibre $7 \mathrm{~mm}$ com alcance de $2.000 \mathrm{~m}$. Ele afirma que uma consequência imediata da morte é o relaxamento total do corpo; porém, a foto mostra que esta mão ainda estava segurando o fuzil.

Por outro lado, o especialista forense afirma que não há explicação possível, se o miliciano estivesse morto, para a mão esquerda estar contraída. Porém, devemos ressaltar que, para os defensores de Capa, este fato demonstraria que teria havido a morte, pois ela (a mão) não aparenta qualquer sinal de defesa do corpo em queda contra o chão. Todavia, para Verdú, esta mão deveria estar absolutamente aberta, isto é, nem contraída nem em posição de defesa para amparar o corpo.

Em suma, ele conclui, o corpo apresentaria uma forma anti-natural de cair. Por isso, não haveria uma explicação racional para um morto cair desta maneira. Observamos assim que as circunstâncias da morte são alistadas e apoiadas na ciência forense e apresentando

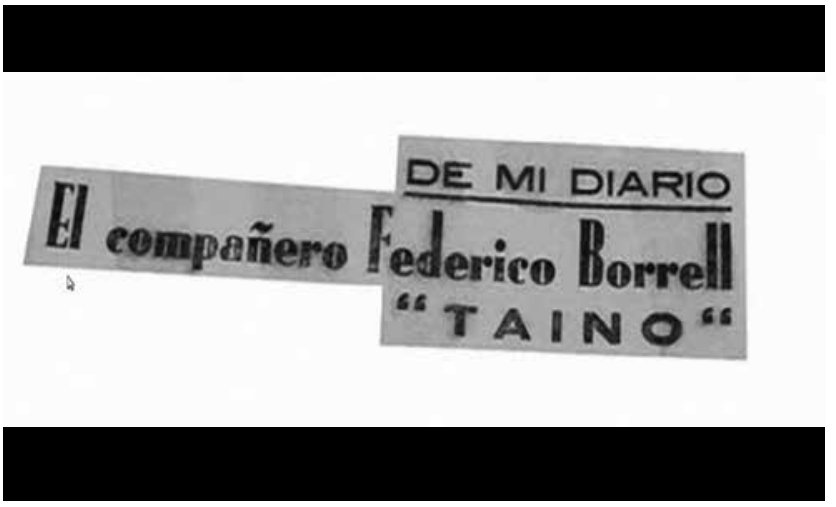

Figura 6 - Prova Documental de que Federico Borrell Teria Morrido em Outro Dia / Fonte: Fotograma do Documentário

modalizações em relação à forma como a fotografia registra a queda do corpo e a ausência de marcas na fotografia do tiro. Tais enunciados enfraquecem a tese de que a foto tenha sido tirada no momento da morte do miliciano.

\section{Quem?}

Esta parte do documentário começa com a seguinte pergunta:"Quem é o miliciano? Quem é o protagonista desta magnífica fotografia?" (Tempo: 28:2028:22/ 74:14min). E então uma voz em off afirma que quando se chegar à identidade do miliciano as polêmicas se acabariam (Figura 5).

O primeiro passo é, então, uma visita a Empar Borrell, sobrinha de Federico Borrell García. Ela relata que, em 1995, o historiador Mario Brotons procurou sua família pedindo-lhes que examinassem umas fotografias do miliciano. A mãe dela teria reconhecido o homem da foto como sendo seu cunhado Federico Borrell.

Ao mesmo tempo em que Empar Borrell faz estas afirmações, começam a aparecer imagens contrastantes do miliciano com fotos de Borrell García. O efeito pretendido sugere que eles parecem ser duas pessoas distintas.

Mario Brotons foi um historiador amador que havia lutado na frente de Alcoy, a mesma de Borrell García, na Guerra Civil. Ele afirmou que havia encontrado evidência, em arquivo de Salamanca, de que somente um homem havia morrido naquele dia, naquela frente: Federico Borrell. Os cineastas, então, procuram os dois filhos de Brotons, que afirmam que o pai nunca teve certeza histórica de que o miliciano seria Borrell García, mas tão somente uma intuição pessoal.

O próximo passo é visitar o Arquivo Histórico de Alcoy. Lá estão arquivados centenas de periódicos. Em um deles - o periódico anarquista Ruta Confederal, de 1937, um ano após a tomada da foto de Capa -, há uma notícia em que um companheiro de Federico Borrell (Figura 6) o homenageia e conta detalhes da sua morte: o relato desta morte não tem qualquer semelhança com a famosa fotografia de Capa. 
Eran las cuatro de la tarde cuando murió el compañero Taino [apelido de Borrell García] [...] Aún le veo parapetado detrás de un árbol, con la sonrisa en la boca, disparando con serenidad y presteza [...] Le veo tendido detrás del árbol que le servía de parapeto [...] ¡Aún después de muerto empuñaba su mano rígida el fusil! (Transcrição a partir do documentário. Tempo: 33:1133:33/74:14min).

Corte.Volta a sobrinha de Borrell García afirmando que ela própria não o conheceu, mas que a mãe dela tinha certeza de que o miliciano morto de Capa era seu tio.

Corte novamente! Entra a ciência forense. Fernando Verdú, já nosso conhecido, é chamado de volta. Numa sequência rápida, são contrastados os rostos do miliciano e o de Federico Borrell, bem como detalhes: dentes, orelhas e dedos. Tudo para realçar as diferenças entre os dois personagens.

Verdú olha as fotos dos dois homens através de uma lente de aumento e diz que se pode afirmar que são duas pessoas diferentes. Em seguida, há o uso de um computador. Ele começa por examinar a formação dentária dos dois homens mostrando que Borrell García tinha uma separação entre os dentes da frente, o que não acontecia com o miliciano, que os têm mais "fechados".

O próximo contraste são as orelhas. Enquanto o miliciano teria orelhas mais "quadradas", Federico Borrell as teria em formato pontiagudo. $\mathrm{O}$ primeiro teria o lóbulo das orelhas pegado ao rosto, enquanto o segundo o teria de forma diferente, separado. E os dedos? Os de Borrell García seriam redondos, mais jovens; já os do miliciano seriam robustos e alongados.

No que diz respeito à idade dos dois personagens, Verdú coloca lado a lado duas fotografias: a de Borrell García é de 1934, e a do miliciano, de 1936, tirada por Capa. A partir deste contraste, ele afirma que se poderia dizer que o primeiro teria entre 22 e 24 anos, enquanto que a foto de dois anos depois mostra um homem bem mais velho, isto é, não uma pessoa de 24-26 anos.

Verdú afirma, para finalizar sua intervenção, que há certezas matemáticas e certezas morais. Do ponto de vista matemático, ele não pode afirmar, com margem segura, que os personagens sejam duas pessoas diferentes. Porém, continua, ele estaria moralmente convicto de que se trata de duas pessoas distintas.

Diferentemente da parte anterior, aqui é a história que, a partir de relatos de personagens e das inscrições, terá uma modalização de natureza positiva em direção à tese defendida no documentário: a partir de relatos de historiadores é retomada a assertiva de que a pessoa da foto não é Frederico Borrel. Do ponto de vista da história, a caixa preta é novamente fechada. Porém, a recorrência novamente à ciência forense traz o reconhecimento de que não há como provar que sejam duas pessoas diferentes. $\mathrm{O}$ argumento de força maior é que a matemática não pode provar que sejam duas pessoas

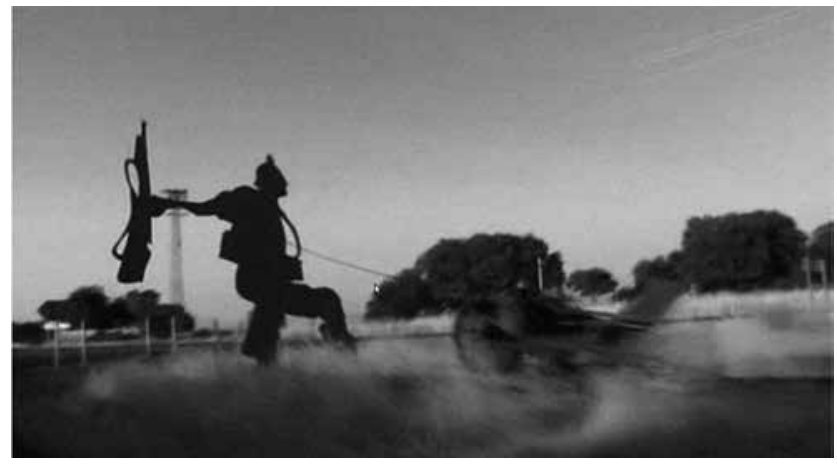

Figura 7. Esculturas do Miliciano Morto na Entrada de Cerro Muriano / Fonte: Fotograma do Documentário

diferentes. Estamos diante do processo de instabilidade constitutiva dos fatos. $\mathrm{O}$ aspecto contingente e coletivo da construção da controvérsia reaparece e a caixa preta é de novo aberta.

\section{Onde?}

A versão oficial de Robert Capa e seus defensores é que a foto teria sido tirada no calor de uma refrega acontecida na localidade de Cerro Muriano, Córdoba. Inclusive, como se pode ver nas primeiras imagens (Tempo: 37:14-37:18/74:14min) desta parte do documentário, há uma identificação, certamente turística, desta comunidade com a famosa fotografia, pois à medida que se avança pela autoestrada em direção à cidade, começam a aparecer esculturas comuns do miliciano morto (Figura 7), justamente reproduzindo a dita foto.

O objetivo dos documentaristas nesta parte é contestar a versão oficial de Capa. Robert Capa, que (supostamente) tirou a foto, voltou ao local do incidente? Não há registros sobre tal fato. Richard Whelan, seu biógrafo e defensor tenaz da versão oficial, visitou o local? Certamente! Mas teve ele os "olhos bem abertos" para as minúcias? Ele parou para assuntar sobre o horizonte da foto em comparação com o horizonte que seus olhos viam, tomado que estava na crença e na defesa da versão oficial? Mas, se ele se interrogou sobre isto, seus olhos estavam treinados o suficiente para perceber detalhes e insignificâncias da topografia local, que escapam à percepção de quem não vive na localidade?

Por isso, é que os cineastas começam esta etapa da controvérsia pela tomada de depoimentos da gente das redondezas. O primeiro testemunho é de um dono de bar da localidade, que revela que todos parecem acreditar que a foto foi realmente tirada, não ali em Cerro Muriano, mas em outra localidade, em Cerro de la Coja, pois as paisagens ao fundo na fotografia de Capa não correspondem a nenhum cenário conhecido pelos habitantes do lugar.

Estamos ainda na fase dos testemunhos advindos do conhecimento popular, isto é da experiência das pessoas comuns. Parte-se, pois, para Cerro de la Coja. O consultado agora é um pastor de cabras - Andrés 
Hidalgo -, que, ao ser perguntado, enquanto segura uma cópia da foto do miliciano, se acredita que aquela mesma foto poderia ter sido tirada nos arredores de onde se encontram, afirma que sim, pois, para ele, a paisagem da foto é semelhante ao recorte das colinas e serras que cercam o lugar. Mas, ainda há dúvidas, pois bem poderia ter sido na localidade de Las Malagueñas, ou mesmo em Virgen de los Pinera, como alguns jornalistas japoneses chegaram a sugerir. É o empilhamento de argumentos contra a versão oficial de Robert Capa.

Desse modo, podemos ver já aqui uma modulação da verdade de Capa: da certeza de Cerro Muriano para as incertezas de três diferentes localidades. Diante de tantas perguntas, o melhor mesmo é alistar mais uma vez a ciência. E ela chega se anunciando através de imagens que relembram aplicativos do Google.com, tais como o Google.Maps ou o Google.Earth.

Especificamente, a Geodésia ${ }^{3}$ é alinhada através do Tenente-Coronel Manuel Illanes. Porém, nem mesmo, neste caso, a ciência é capaz de fechar a caixa-preta da foto de Capa, pois, na comparação do horizonte presente na foto de Capa com os horizontes dos três locais considerados pelos documentaristas, não é possível concluir em que local ela teria sido tirada, assim nos afirma Illanes.

Há neste momento uma volta ao conhecimento comum, popular. Vem ao nosso encontro Juan José Obrero, dono do Bar X, em Cerro Muriano, que teria conduzido os jornalistas japoneses por suas andanças por Virgen de los Pinera, e mesmo posado para eles como se o miliciano morto fosse. E ele mesmo acrescenta que os japoneses estavam somente em busca de um lugar que se assemelhasse ao horizonte fotografado por Capa.

Dessa forma, eliminada a localidade de Virgen de los Pinera, é preciso voltar a Cerro de la Coja e a Las Malagueñas para tentar fechar a caixa-preta sobre a foto de Capa, pelo menos neste aspecto. Porém, aqui, o que se nos aparece é uma dificuldade: se a foto não foi tirada em Cerro Muriano, restam somente especulações ao se tentar comparar uma paisagem de uma cópia de uma foto "borrada" tirada há 70 anos com a paisagem atual, que certamente passou por modificações. Assim é que Cerro de la Coja seria candidato a local mais provável porque tem uma aparência mais próxima do cenário que aparece na foto de Capa.

Como não é possível fechar a caixa-preta que foi aberta nos tópicos anteriores, parte-se para mais uma especulação. Com efeito, na discussão, inconclusa, sobre em que lugar a foto teria sido tomada, volta-se para a especulação se não teria sido Gerda Taro a verdadeira autora da foto já que, se argumenta, as máquinas usadas por ela e Capa seriam intercambiáveis ${ }^{5}$. Em outras palavras, o empilhamento dos diversos argumentos leva à sugestão de que a foto de Capa, não somente teria sido encenada, mas ela não seria de sua autoria, mas de Gerda Taro. Em suma: Robert Capa teria nos enganado duas vezes.

Nesta parte do documentário há um aspecto interessante: além das ciências já alistadas anteriormente, alista-se o conhecimento do senso comum. Tal aspecto nos faz retomar a ideia de Latour \& Woolgar (1997) e Latour (2000) de que não há separação entre conteúdo e contexto. Não há um lugar privilegiado para o conhecimento científico em relação aos outros tipos de conhecimento, tal como neste caso, o conhecimento do senso comum. Ou seja, não podemos isolar os fatores sociais que circundam a produção da ciência e, no nosso caso aqui específico, a construção de uma dada controvérsia.

\section{Quando?}

No processo de questionamento da verdade recebida sobre a fotografia de Capa, procura-se abrir esta caixa-preta também através da desmontagem de quando a fotografia teria sido tomada, isto é, a hora em que Capa teria capturado o miliciano sendo morto. De acordo com a versão oficial, a foto teria sido tirada às $17 \mathrm{hs}$.

Os documentaristas, em seu processo de alistamento das ciências e seus artefatos, começam por enumerar o que pode ser considerado como ponto fraco da argumentação dos defensores de Capa: a sombra do miliciano na fotografia. Se observarmos bem, eles parecem nos dizer, a sombra projetada pelo miliciano caindo sobre a grama do declive não condiz com a hora em que Capa teria tomado a famosa foto, segundo a versão estabelecida pelo próprio e aceita por seus defensores. Para isto, eles mostram a sombra de Andrés Hidalgo, o já conhecido pastor de cabras, cuidando delas, às $11 \mathrm{hs}$ da manhã, em Cerro de la Coja. Em justaposição com a foto de Capa, as sombras são compatíveis entre si, o que enfraqueceria a versão de que "A Morte do Miliciano" houvera sido tomada às $17 \mathrm{hs}$.

Dessa forma, na tentativa de estabelecer uma base científica para os seus argumentos, são rapidamente listados uma série de atores humanos e não-humanos: a própria sombra na fotografia (como fenômeno físico), a posição do sol, o Laboratório do Observatório de Greenwich, capaz de fornecer a hora matemática, um astrofísico, uma fórmula matemática e um computador com um software capaz de fazer cálculos e nos fazer voltar no tempo, não a uma tarde (como querem os defensores de Capa), mas a uma manhã de 5 de setembro de 

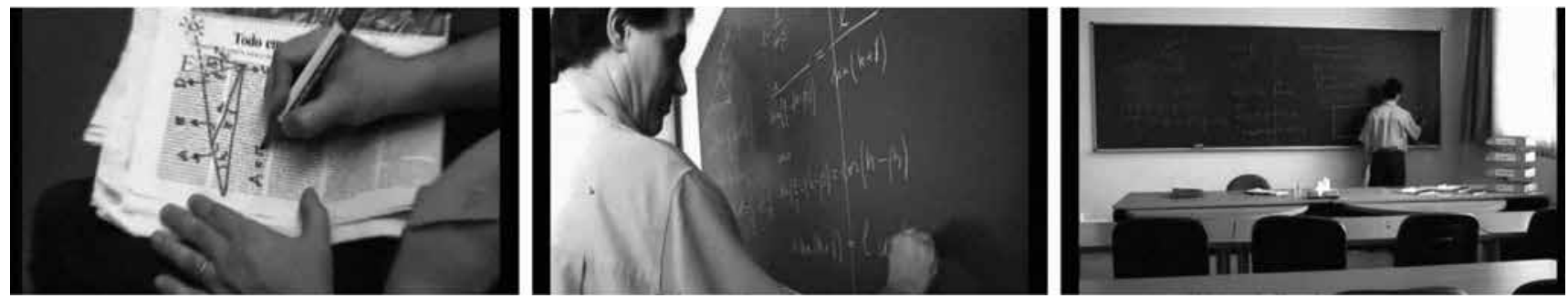

Figura 8 - Demonstração Matemática Que Demonstra em Horário A Foto Teria sido Tirada / Fonte: Fotograma do Documentário

1936 em plena Guerra Civil Espanhola (como querem os documentaristas).

Como se sabe, a divisão do globo terrestre em meridianos tornou muito mais fácil o cálculo das horas nos diferentes regiões e países. Permitiu também, por exemplo, a localização de navios e aviões que trafegam nos mares e céus do planeta. Esta divisão foi estabelecida tendo como ponto de partida o meridiano que passa sobre a localidade de Greenwich, no Observatório Real, nos arredores de Londres.

Então, o primeiro passo dos documentaristas é resolver uma questão básica: o horário de 2007 (data do filme) é o mesmo de 70 anos atrás, isto é, 1936? É aí que entra mais um ator não-humano: o Observatório de Greenwich. Esta questão é rapidamente resolvida: basta uma ligação e uma voz com tom magnético responde que "não" e que esta diferença seria de cerca de duas horas, devida à própria rotação da terra (Tempo: 45:10-45:33/74:14min).

Mas esta é somente a primeira informação necessária para inverter uma das verdades recebidas acerca da foto de Capa: a de que ela teria sido tirada ao entardecer daquele fatídico dia. Com esta informação em mãos e a certeza de que a sombra projetada pelo miliciano caindo é incompatível com a hora apregoada por Capa, traz-se agora em cena um astrofisico (Enric Marco, da Universidade de Valença). Os documentaristas fazem questão de reafirmar a crença bastante difundida de que os “números não mentem”. E, se os números não mentem, resta fácil abrir mais uma brecha na versão capiana e de seus defensores.

O referido astrofisico aparece em um trem/metrô fazendo um desenho com letras e números em que se supõe que esteja tentando representar a inclinação do sol naquele dia de 70 anos atrás. Em seguida, a cena já é uma sala de aula em que a montagem em cenas rápidas mostra-o derivando uma fórmula e repetindo várias vezes a seguinte frase: "Tudo se pode explicar com números". E então ele anuncia lenta, mas triunfalmente: "Esta é a fórmula da fotografia!" (Tempo: 46:2246:24/7:14min), isto é, a fórmula (um agente conceitual, para Pickering, 1995, p.114ss) capaz de indicar o horário em que Capa teria tirado a foto (Figura 8).

O próximo alistamento é um computador com um software capaz de fazer os cálculos necessários para a determinação do horário em que Capa, independentemente de a foto ter sido ou não encenada, teria captu- rado a famosa cena. O astrofisico alerta (Figura 9): "Sem referências geográficas claras, os cálculos nos oferecem algumas horas possíveis da realização da fotografia, teria sido às nove da manhã ou às três da tarde" (Tempo: 46:33 46:44/74:14min).

Mesmo que os números não mintam ou que a realidade possa ser explicada por números, os cálculos mostram um intervalo de cerca de seis horas, pois, como o cientista alertara, faltam dados mais precisos sobre o local onde a foto teria sido tirada.

Porém, deve-se atentar para o fato de que, mesmo com a imprecisão dos cálculos, já é possível antever o argumento dos documentaristas: Capa e seus defensores mentiram e mentem quanto ao horário de realização da foto (primeiro momento da modulação).

Mas, há mais a ser feito: o software é capaz de nos transportar de volta à manhã do dia 5 de setembro de 1936. Não há margens para dúvidas: as rápidas imagens em sucessão nos transportam para o passado como em uma máquina do tempo. E o turno do dia é encontrado por informações adicionais históricas. A frente de batalha era ao sul do local onde a foto teria sido tomada. Assim, o miliciano certamente estaria vindo daquela direção. Com a combinação lógica destas informações com o que se pode traduzir das informações prestadas pelo computador e seu software, chega-se a uma hora precisa em que Capa teria tirado a sua famosa foto: nove horas da manhã.

Além disso, outra informação oferecida a partir do software, é ser capaz de nos dizer que naquele 5 de setembro o sol se pôs às 18:30h, precisamente. Ora, como a foto poderia ter sido tirada na hora dita por Capa se

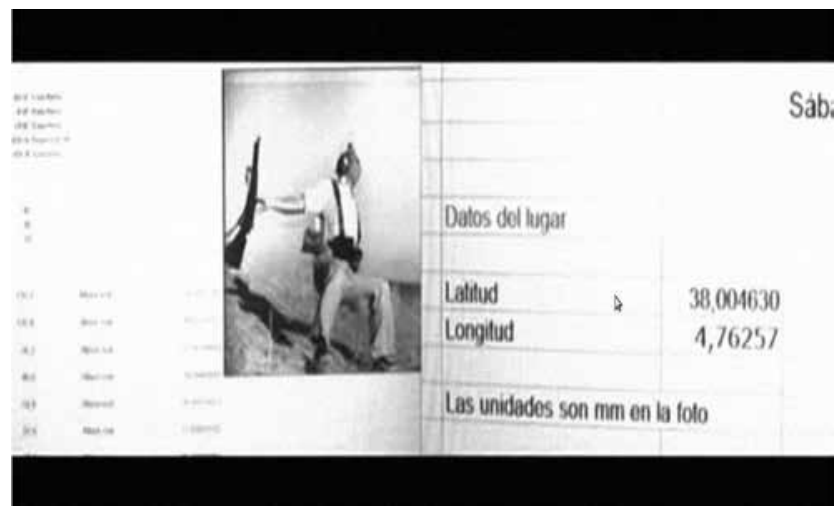

Figura 9. Os Cálculos Dão as Horas Possíveis, Não as Horas Exatas / Fonte: Fotograma do Documentário 
Vênus e Júpiter apareceram no horizonte, e, logo em seguida, Mercúrio se juntou a eles no final daquela tarde? Porém, não há "sombra" destes planetas no horizonte da fotografia de Capa! Se a foto tivesse sido tirada na hora relatada por Capa estes planetas, certamente, parece ser sugerido pelo argumento do astrofísico, não estariam ausentes da foto.

Se Richard Whelan, Cornell Capa e outros, preferem continuar a acreditar na e a defender a versão de Capa, pior para eles, pois "os números falam” e mostram que mesmo os astros celestes se alinharam contra o famoso fotógrafo. É esta versão de uma nova caixa-preta que o documentário tenta estabelecer.

Com efeito, o alistamento realizado pelos cineastas, com a ajuda do Laboratório de Greenwich, de um astrofísico, de uma fórmula matemática, de um computador e seu software específico, do sol e de três planetas, ajuda mais ainda na abertura da caixa-preta em torno da fotografia de Robert Capa, caixa esta que começou a se fechar em 5 de setembro de 1936 e que permaneceu assim por muito tempo. Ou seja, os cineastas chegam à seguinte reformulação do entendimento comum desde Capa: a foto não foi tirada às $17 \mathrm{hs}$, mas às $9 \mathrm{hs}$. Estamos diante de uma nova caixa-preta.

O que se diferencia nesta parte do documentário é que um dos argumentos de força maior na controvérsia instalada é apresentado a partir do uso de um ator não humano - um computador com um software - que estabelece uma nova caixa-preta. Para Latour (2011) ao tratarmos as controvérsias não podemos restringir apenas aos atores humanos. É preciso rastrear os instrumentos alistados que permitem aos atores estabilizar ou instabilizar as controvérsias.

\section{Como?}

A pergunta se refere, obviamente, à performance de Robert Capa e sua máquina fotográfica no momento da captura da famosa imagem. A que distância estava Capa do miliciano? Que tipo de fotografia (tamanho, formato etc) tirava uma Leica (a máquina de Capa)? Em que posição estava Capa?

Uma versão estabelecida ${ }^{6}$ por Capa e seus defensores pode ser resumida nas seguintes palavras, em uma entrevista dada por Robert Capa à rádio WBNC, em 20 de outubro de 1947:

Ocurrió en España. Fue al principio de mi carrera como fotógrafo, y a comienzos de la guerra civil española.Y la guerra tenía un lado romántico, si se puede decir algo así... Estaba en una trinchera con unos veinte hombres armados con viejos fusiles. En la ladera de enfrente había una ametralladora insurgente. Los hombres dispararon a la ametralladora durante cinco minutos, luego se levantaron y dijeron: ¡Vamos! Salieron de la trinchera avanzando hacia la ametralladora y como era de esperar la ametralladora abrió fuego, ¡dim, dom! Los que quedaron con vida regresaron y volvieron a disparar al tuntún hacía la ametralladora, que fue lo suficientemente inteligente como para no responder. Y después de cinco minutos volvieran a decir: ¡Vamos! Y salieron otra vez. Se repitió la escena tres o cuatro veces. La cuarta vez me puse la cámara sobre la cabeza $\mathrm{y}$, sin mirar siquiera, hice la foto cuando se acercaban a la trinchera (Grifos nossos) ${ }^{7}$.

Corte! Estamos em um estúdio fotográfico. Josep V. Monzó, diretor de fotografia do Instituto Valenciano de Arte Moderno (IVAM), reconstitui a cena da foto de Capa em estúdio. O objetivo é claro: testar com a ajuda dos princípios físicos da fotografia a versão difundida por Capa acerca das condições em que teria capturado a foto do miliciano.

Monzó coloca um modelo humano na posição do miliciano morto. Olha pelo visor da câmera, olha para uma cópia da foto de Capa, checa a posição do modelo, dá-lhe instruções quanto ao posicionamento, para que corresponda o mais fielmente possível à foto "original”. Tira, então, uma foto, que aparece em P\&B. Passa, então, a fazer riscos no chão do estúdio. São marcas para estabelecer a posição de Capa em relação ao miliciano.

Corte! A astrofísica e seus instrumentos são alistados novamente. A narração em off estabelece a versão oficial de Capa: ele estaria a cerca de 20 metros do fotografado no momento em que tirou a foto. É esta versão que vai ser desafiada pelo alistamento de novos agentes humanos e não-humanos.

Enric Marco, nosso já conhecido astrofisico, entra novamente em cena. Recomeçam os cálculos e uma nova agência conceitual - o teorema de Tales - é alistada para demonstrar que, na verdade, Capa estava somente a cinco metros (1/4 da distância originalmente apregoada) do miliciano. Por seu turno, Monzó conclui, utilizando noções elementares da fisica aplicada à fotografia, que a foto, na verdade, teria sido tirada com Capa distando 4,5 metros do miliciano. Mais uma vez, a versão sustentada pelos defensores de Capa é posta em xeque pela utilização da ciência e seus artefatos.

Agora, a própria Leica é alistada. Monzó manipula uma Leica III-a (modelo 1935), objetiva Elmar 50mm f/3.5, velocidade de obturação 1/1000sg, o mesmo modelo usado por Robert Capa e Gerda Taro na Guerra Civil Espanhola.

6 Há pelo menos mais uma versão difundida pelo próprio Capa: a de que ele estava junto ao miliciano em uma trincheira, quando este se levantou e foi atingido. Mas aqui, a maioria dos analistas concorda, há uma inconsistência lógica, pois o pretenso morto teria de ter sido fotografado pelas costas e não de frente.

7 trecho é uma transcrição das legendas do documentário espanhol da fala de Capa (Tempo: 52:47-53:54/74:14min) 
Sabemos, então, que as máquinas fotográficas utilizadas, de forma intercambiável, por Gerda Taro e Robert Capa durante este período eram uma Rolleiflex e uma Leica. A primeira tirava fotos quadradas e a segunda, retangulares ${ }^{8}$. Monzó, em cena novamente, manipula a Leica, modelo de 1935, e mostra que o ajuste da máquina ao olho humano permite concluir, a partir da forma estética que consagrou Robert Capa, isto é, ligeiramente fora de foco (Cf. Capa, 2010), que a foto foi focada e não tirada como narrada: "me puse la cámara sobre la cabeza $\mathrm{y}$, sin mirar siquiera, hice la foto cuando se acercaban a la trinchera". O estilo "borrado" de Capa é visível, segundo Monzó, na foto do miliciano. E este efeito só poderia ser conseguido pela interação consciente entre fotógrafo e máquina, isto é, a curta distância (compatível com os 4,5-5 metros e não com os 20 metros da versão capiana) em que o fotógrafo moveu a máquina ligeiramente no sentido horizontal para conseguir o efeito desejado, quer dizer, ligeiramente fora de foco.

Desta forma, mais uma vez, fica claro, seguindo as indicações de Latour, como o fato social é construído pela tecnologia. Os fatos sociais são fabricados justamente a partir das diversas leituras dos artefatos, das interpretações e inscrições produzidas a partir desses artefatos. Como temos visto até aqui, são essas idas e vindas dos enunciados e de como estes vão sendo transformados ou reafirmados que dá visibilidade ao caráter coletivo e processual das diversas associações estabelecidas dentro de uma determinada controvérsia.

\section{Por Quê?}

Seguindo o roteiro estabelecido pelos próprios "nativos", isto é, os autores do documentário, resta saber porquê há (ou havia) tão grande defesa e manutenção de secretismo em torno desta foto de Capa. Por que

\section{Para: "Richard whelan" \\ Dear Mr. Whelan, \\ We've read your essay with a}

Figura 10 - Troca de E-mails Entre os Cineastas e o Biógrafo de Robert Capa / Fonte: Fotograma do Documentário

Cornell Capa e Richard Whelan mantêm à distância todos aqueles que questionam a foto de Capa? Por que Whelan foi capaz de chamar os cineastas de neo-franquistas e neo-fascistas (Tempo: 67:46-67:56/74:14min) se eles estavam somente tentando entender e responder questões referentes às condições em que Capa teria tirado a foto do miliciano?

São perguntas que se fazem a dupla de cineastas, pois Whelan parece acuado diante da quantidade de aliados que eles alistam, aliados estes bastante poderosos. É por isso que nos interessa seguir os seus usos da ciência e seus artefatos no desvelamento da foto de Capa. Embora esta última sessão do documentário esteja mais voltada para as inconsistências lógicas na narrativa oficial acerca da foto em questão, ainda assim é possível encontrar o alistamento de determinadas ciências: a medicina forense e a arquivologia. A reprodução das fotos comumente mostra algumas delas sem que saibamos em que sequência elas foram tiradas. Qual foi a primeira foto da sequência? E a última? Isto é uma informação importante porque poderia esclarecer se a versão de Capa e seus defensores ou a versão dos seus questionadores é a correta? Sim, porque se a foto (Figura 11) em que aparecem vários milicianos levantando as armas em sinal de alguma comemoração foi tirada

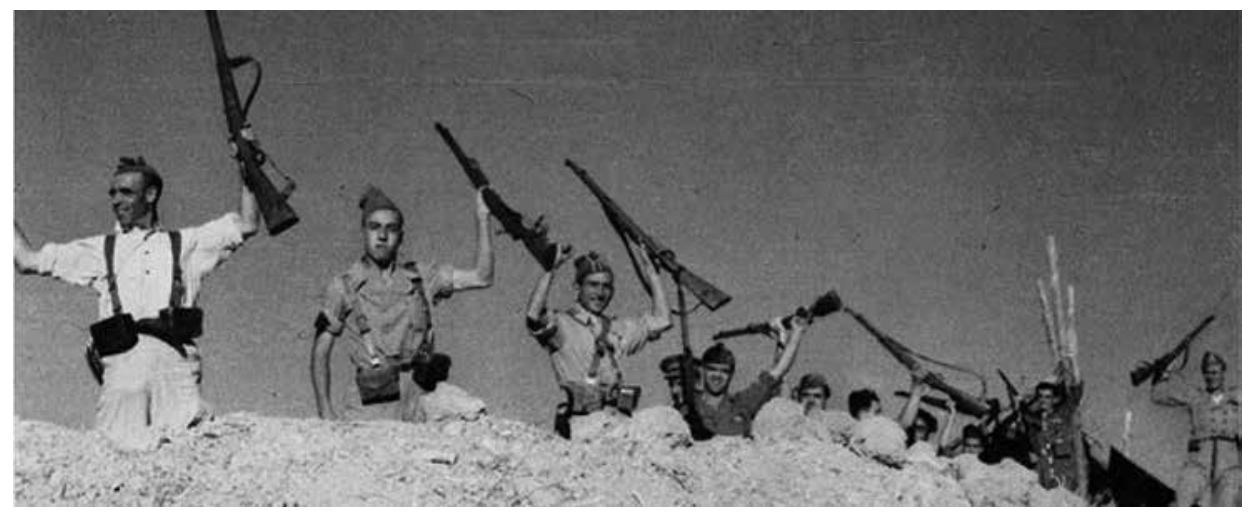

Figura $11^{9}$

8 Esta informação aparece meio "solta" no documentário, a não ser pelos seguintes fatos: é mostrado um retrato de Robert Capa com uma Rolleiflex pendurada no pescoço ao lado de uma foto tirada por esta mesma marca, enquanto, em seguida, mostra-se um retrato de Gerda Taro, fotografando com uma Leica, justaposto a uma foto tirada por esta máquina. Estariam os documentaristas sugerindo, mais uma vez, que Taro, em lugar de Capa, é quem teria tirado a foto do miliciano? É uma pergunta que, no momento, foge ao escopo deste artigo.

9 Fonte: https://www.google.com.br/search?q=robert+capa\&source. Acesso: 05/06/2014. 


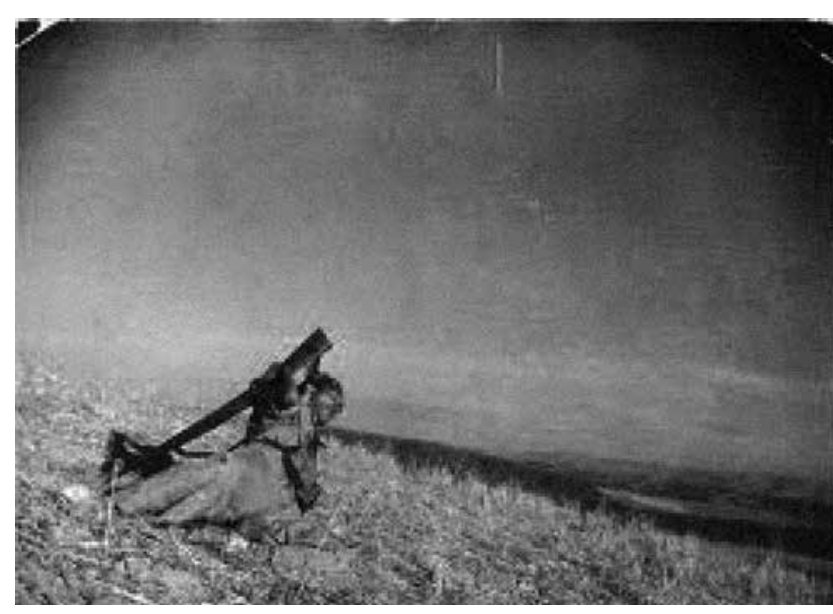

Figura $12^{10}$

após a foto do miliciano morto, pode-se provar que Capa nos enganou, já que o "morto" aparece vivo nesta foto (Primeiro miliciano à esquerda). Se o caso fosse o contrário, poder-se-ia ter uma ideia mais segura quanto à morte do miliciano.

Uma busca nos arquivos da revista francesa $V u$, a primeira a publicar as fotos de Capa, permite aos documentaristas mostrar que há também um segundo miliciano morto (Figura 12). Neste momento, já não são mais cinco fotos, mas seis, sem que se saiba a sequência delas. Temos também dois mortos em lugar de um.

É neste momento de visita ao passado, presente na revista mencionada, que entra em cena novamente a medicina forense porque houve coisas estranhas ocorrendo naquele dia no lugar - que não seria Cerro Muriano -, como já vimos acima. Pois veja-se a foto a seguir:

Que há de errado com ela? À primeira vista, aparentemente nada. Mas, paremos! A medicina forense pode nos ajudar aqui. Ela é alistada para "desmascarar" Capa. Então, retomemos: o que mostra ela? Dois homens, aparentemente, mortos. Sim. Porém, a medicina forense nos diz: "só se morre de boca para cima ou de boca para baixo", nas palavras dos cineastas (Tempo: 62:06-62:08/74:14min). Então: podemos perguntar: houve mortes naquela hora, naquele dia, naquela região, presenciadas e fotografadas por Robert Capa (ou Gerda Taro)? Ao que parece, não! Pois a medicina forense é capaz de nos dizer que estes dois homens retratados na figura 13 , acima, não estavam mortos no momento em que foram fotografados. Se ninguém morre naquela posição, isto é, em perfeito equilíbrio, é que Capa os fotografou em pose. E, obviamente, nossa compreensão da importância e do impacto sociais das fotos de Capa ao longo destes anos pode ser mudada.

Assim, nesta parte final do documentário a arquivologia é alistada, conjuntamente com a medicina forense, para reafirmar que a foto de Capa é uma encenação da morte de uma pessoa da qual não se consegue identificar. Ao final da análise dos diversos empilha-

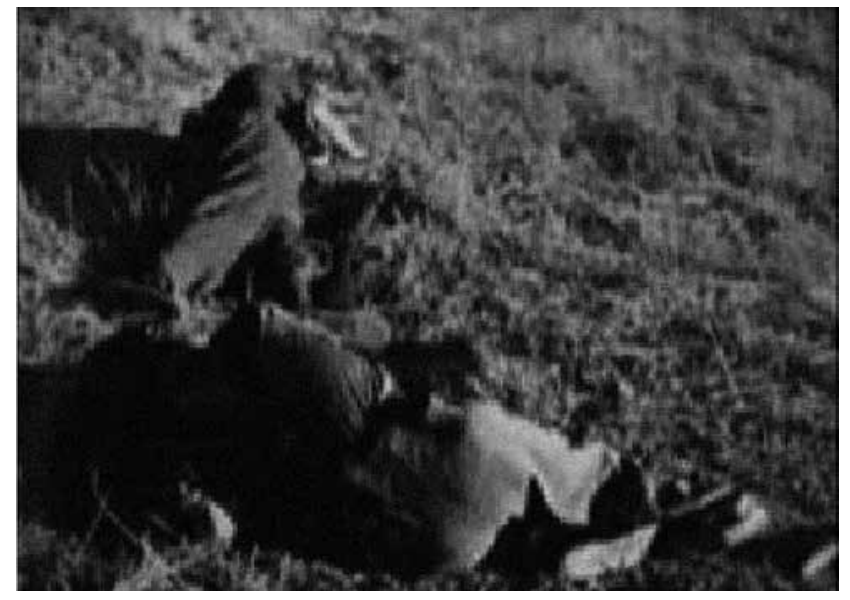

Figura $13^{11}$

mentos de fatos, artefatos, atores humanos e não-humanos, percebemos que o documentário foi sendo montado a partir de diversas modalizações dos enunciados presentes na história oficial que foram contrapostos e transformados em argumentos de força maior na defesa da tese defendida.

\section{Considerações Finais}

Como tratar uma controvérsia sociologicamente do ponto de vista da Sociologia da crítica? Esta é a pergunta que orientou a construção desse artigo. A partir de um exemplo empírico - um documentário que recupera um debate público no campo do fotojornalismo - quisemos ilustrar um caminho teórico-metodológico possível, entre outras possibilidades, para análise de controvérsias sociais.

A sociologia da crítica concebe o social não como uma esfera exclusiva ou um objeto particular, mas apenas como um movimento peculiar de reassociação e reagregação (Cf. Latour, 2012, p.25). Nessa direção, o autor nos oferece um caminho metodológico para acompanhar o que é realizado por humanos e não-humanos no processo de estabilização das controvérsias. As controvérsias, nessa perspectiva, são vistas como o que permite o estabelecimento do social e a contribuição das várias ciências na construção das controvérsias.

Nesse sentido, seguimos as regras metodológicas latourianas ao analisar a controvérsia em foco neste artigo: a) os esforços utilizados pelos documentaristas no alistamento de humanos e não-humanos foram simetricamente considerados na resolução da controvérsia tratada; b) tratamos as inscrições não de forma isoladas mas interligadas e transformadas pelos diversos atores envolvidos; c) seguimos os alistamentos dos diversos personagens e observações as modalizações que os enunciados desses personagens sofreram sempre considerando o campo agnóstico construído no documentário. 
Parece-nos que, a principal contribuição deste artigo é atentar para a possibilidade de aplicação das regras metodológicas de Latour no que se refere ao modelo de fabricação da ciência a outros campos de conhecimento. Também, a dissecação dos alistamentos da ciência na autópsia realizada do documentário analisado parece sugerir um caminho para a análise de argumentos em outros contextos de controvérsias distintas.

Com relação à fotografia de Robert Capa, nossa análise procurou demonstrar que parece ser quase impossível resolver, nos marcos das ciências sociais, a questão da feitura da foto "A Morte do Miliciano", a não ser que o cientista social insista em se pôr de um dos lados da disputa talvez mais por simpatia com uma tese ou outra. Dessa forma, procuramos ressaltar o potencial analítico de uma sociologia da crítica (em lugar de uma sociologia crítica) frente às mais diversas controvérsias que perpassam as sociedades humanas desde tempos imemoriais.

\section{Referências}

ALENCAR, Rosane. Discurso científico e construção coletiva do saber: a dimensão interativa da atividade acadêmico-científica. Recife, 2004. Tese (Doutorado em Sociologia) - Universidade Federal de Pernambuco.

CAPA, Robert. Ligeiramente fora de foco. São Paulo: Cosac \& Naify, 2010.

CHATEAURAYNAYD, Francis. Making tangible facts: investigations and the sudden appearance of proof. Paris: GSPR-EHESS, 2004.

On argumentative constraints: forms of argumentation between deliberative frameworks and powers of political expression. Paris, GSPR-EHESS, 2007.

Portraits d'experts en statuettes égyptiennes: a propos de la querelle d'expertise autour de Sésostris III. Paris: GSPR-EHESS, 2009a.

Public controversies and the pragmatics of protest: toward a ballistics of collective action. Paris: GSPR-EHESS, 2009b. LATOUR, Bruno. Pasteur: guerre et paix, suivi de Irréductions. Paris: A.-M. Métaillé, 1984.

Ciência em ação: como seguir cientistas e engenheiros sociedade afora. São Paulo: Editora da Unesp, 2000.

. Reagregando o social: uma introdução à teoria do ator-rede. Salvador/Bauru: Edufba/Edusc, 2012.

. \& WOOLGAR, Steve. A vida de laboratório: a produção dos fatos científicos. Rio de Janeiro: Relume Dumará, 1997.

MARTINS, José de Souza. Sociologia da fotografia e da imagem. São Paulo: Editora Contexto, 2008.

PICKERING, Andrew. The mangle of practice: time, agency, and science. Chicago e Londres: University of Chicago Press, 1995. WHELAN, Richard. Robert Capa: a biography. Lincoln: University of Nebraska Press, 1994.

"Robert Capa's falling soldier: a detective story". Aperture, n. 166: 48-55, 2002.

YOUNG, Cynthia. The Mexican suitcase. Londres: Steidl, 2010.

\title{
Vídeos
}

- La Sombra del Iceberg de Raúl M. Riebenbauer y Hugo Doménech. DACSA: 2007

- Caso Abierto ¿Es un Montaje la Foto del Miliciano de Robert Capa? (Francisco Pérez Abellán) (Fonte: https://www.youtube.com/watch? $\mathrm{v}=\mathrm{QeY} 4$ orDxMnw). Acesso: 19/5/2014.

- Chema a las 11 Entrevista a Raúl Riebenbauer (Fonte: https://www.youtube.com/watch?v=FLm-OVSuow0). Acesso: 19/5/2014.

- “La Sombra del Iceberg”, Raúl Riebenbaguer, Revista Lima Gris (Fonte: https://www.youtube.com/ watch?v=WrZ-LyvMlO0). Acesso: 19/5/2014.

- NNfotografostrailer XV Conversatorio 'La sombra del Iceberg', Raúl Riebenbauer (Fonte: https:// www.youtube.com/watch? $=6$ isfnt_EkcU). Acesso: $19 / 5 / 2014$

\section{Photography and Scientific Enlistment: An Analysis of a Controversy on Authenticity}

\begin{abstract}
In this paper we analyse disputes on a photography taken by Robert Capa titled 'The Death of a Militiaman'. We use Bruno Latour' sociology of associations to understand two different positions regarding this photography, one which holds that it was posed and another which holds that it was taken et the very moment of the death of the militiaman. In order to that, we analyse a documentary in which science and its artefacts are used by the filmmakers to support a given position. Finally, we conclude by showing that the usefulness of a sociology of associations is that it allows us to analyse the several arguments set by the contenders themselves in order to get a dispute resolved.
\end{abstract}

Keywords: Photography; Robert Capa; Science; Scientific Instruments; Sociology of Associations. 


\section{Fotografía y alistamientos científicos: en torno a una controversia acerca de la autenticidad}

\section{Resumen}

Analizamos las controversias en torno a la fotografia intitulada "Muerte de un Miliciano", de Robert Capa, a la luz de la Sociología de las Asociaciones de Bruno Latour. Acompañamos el desarrollo de los debates entre dos posiciones antagónicas (una que dice que la foto habría sido posada y la otra que afirma que Capa realmente habría fotografiado a alguien en el momento mismo de su muerte) a través del uso de un documental en el que la ciencia y sus artefactos son alistados para defender una determinada posición. Concluimos que, lejos de intentar resolver de modo sociológico la controversia, la Sociología de las Asociaciones nos permite tener un entendimiento de los diversos argumentos puestos a prueba por las partes que están en disputa.

Palabras clave: Fotografia; Robert Capa; Ciencia; Instrumentos Científicos; Sociología de las Asociaciones.

Data de recebimento: 07-10-2014

Data de aceitação: $01-02-2015$ 